\title{
Investigation into the Physical Mechanism and Influencing Factors of Sympathetic Inrush for Transformers in Series
}

\author{
Fang Peng ${ }^{1,2}$ and Houlei Gao ${ }^{1,2}$ \\ ${ }^{1}$ School of Electrical Engineering, Shandong University, Jinan, China \\ ${ }^{2}$ Key Laboratory of Power System Intelligent Dispatch and Control of Ministry of Education, Shandong University, Jinan, China \\ Correspondence should be addressed to Houlei Gao; houleig@sdu.edu.cn
}

Received 20 July 2017; Revised 13 October 2017; Accepted 13 November 2017; Published 11 December 2017

Academic Editor: Guido Ala

Copyright (c) 2017 Fang Peng and Houlei Gao. This is an open access article distributed under the Creative Commons Attribution License, which permits unrestricted use, distribution, and reproduction in any medium, provided the original work is properly cited.

\begin{abstract}
Sympathetic inrush is a magnetizing inrush phenomenon generated in an in-service transformer, when a nearby transformer in series or in parallel is energized. This phenomenon lasts longer than the general inrush and can cause protection maloperation. The study focuses on sympathetic inrush in series transformers. Flux linkage expressions for the series transformers are derived using the Laplace transform. The residual flux, switching angle, and system impedance factors are included in the expressions. The physical mechanism of the sympathetic inrush for series transformers is explained based on the characteristics of the flux linkages. The interaction between the saturated transformers during sympathetic inrush is also investigated. Moreover, the influence of the switching angle, residual flux, system impedance, and load on the inrush currents is analyzed and validated.
\end{abstract}

\section{Introduction}

The magnetizing inrush phenomenon has been well known since the transformer was first used in energy conversion. This phenomenon may cause maloperation of the current differential protection of the transformer. Moreover, the large electromagnetic forces in the transformer windings can damage the insulation of the transformer [1], and the voltage decreases can lead to poor power quality $[2,3]$ during magnetizing inrush. Magnetizing inrush can be classified into energization inrush, sympathetic inrush, and recovery inrush [4]. Energization inrush occurs in the transformer being energized, as a result of the reapplication of the system voltage to the transformer. When one transformer is in service and the other (in series or in parallel) is energized, sympathetic inrush occurs in the in-service transformer. Energization inrush also occurs in the energized transformer and is called initial inrush hereinafter. Additionally, the recovery inrush is generated during the restoration of the voltage after clearance. The present study focuses on sympathetic inrush.

Several maloperation cases of current differential protection due to the sympathetic inrush have been reported [5]. Generally, the second harmonic component of the sympathetic inrush is high [6]. Thus, the second harmonic restraint algorithm is effective in preventing the protection of the in-service transformer from maloperation. However, the initial inrush and sympathetic inrush decay more slowly than the energization inrush in the single transformer due to the sympathetic interaction between the transformers [7]. Current transformer saturation caused by the long-lasting inrush current can decrease the second harmonic content, potentially causing the second harmonic restraint algorithm to fail [8-10]. Then, maloperation of the current differential protection of the in-service transformer will occur. Moreover, the sympathetic inrush may cause maloperation of other types of protection, such as the differential protection of the nearby generator and overcurrent protection, which leads to significant concern $[8,11]$.

The mechanism of sympathetic inrush for transformers in parallel has been investigated previously [12-14]. However, no study has been performed on transformers in series (called series transformers below). In this context, the present study aims to perform an analysis of sympathetic inrush for series transformers. Their flux linkage expressions are derived; then, the mechanism of sympathetic inrush and the interaction between the series transformers are explained using the 
characteristics of the flux linkages. Moreover, the impacts of several factors including the switching angle, residual flux, system impedance, and load are also investigated. A practical model is used in the case studies to demonstrate the theoretical analysis.

The rest of the paper is organized as follows. In Section 2, the equivalent model of series transformers is presented, and the flux linkage expressions of the series transformers are derived based on the Laplace transform. In Section 3, the physical mechanism of the sympathetic inrush for series transformers is explained. In Section 4, the characteristics of the flux linkages under various levels of magnetizing inductance and the effect of transformer saturation on the inrush currents are investigated. In Section 5, the influence of the switching angle, residual flux, system impedance, and load on the sympathetic inrush is analyzed and verified. Finally, conclusions are drawn in Section 6.

\section{Equivalent Model of Series Transformers during Sympathetic Inrush}

2.1. Series Transformers and Equivalent Model. Series transformers are generally used in a step-down distribution system connected to large and special power consumers, such as traction systems, steel mills, and electric boilers. The series transformers are shown in Figure 1. $u_{s}$ is the power system equivalent source, and $Z_{S}=R_{S}+j \omega L_{S}$ is the equivalent impedance, where $\omega$ is the angular frequency. The circuit breaker $(\mathrm{CB})$ is closed and T2 is energized. Initial inrush in $\mathrm{T} 2$ and sympathetic inrush in $\mathrm{T} 1$ are generated.

An equivalent $\mathrm{T}$ circuit is used to represent the transformer [15]. Thus, the equivalent circuit of series transformers is shown in Figure 2, where the symbols represent the following:

$R_{c 1}$ and $L_{m 1}$ : the core loss resistance and magnetizing inductance of the iron core of T1,

$R_{c 2}$ and $L_{m 2}$ : the core loss resistance and magnetizing inductance of the iron core of $\mathrm{T} 2$,

$R_{11}$ and $R_{12}$ : the primary and secondary winding resistance of $\mathrm{T} 1$,

$R_{21}$ and $R_{22}$ : the primary and secondary winding resistance of T2,

$L_{\sigma 11}$ and $L_{\sigma 12}$ : the primary and secondary winding leakage inductance of $\mathrm{T} 1$,

$L_{\sigma 21}$ and $L_{\sigma 22}$ : the primary and secondary winding leakage inductance of $\mathrm{T} 2$.

All parameters are normalized to the primary side of T1.

2.2. Flux Linkage Deviation. The equivalent circuit is simplified as in Figure 3 to investigate the transformer flux linkages. First, the current in the iron core consists of the core loss component and magnetizing component. The core loss resistance can be ignored since the core loss component is much smaller than the magnetizing component [13]. Second, the leakage inductance of the windings is far smaller than the magnetizing inductance of the iron core when the transformer is not saturated; therefore, $L_{\sigma}$ can be neglected. Third, the secondary branch of T2 is inactive due to the lack of load. In addition, let $R_{0}=R_{S}+R_{11}, R_{1}=R_{12}, R_{2}=R_{21}$,

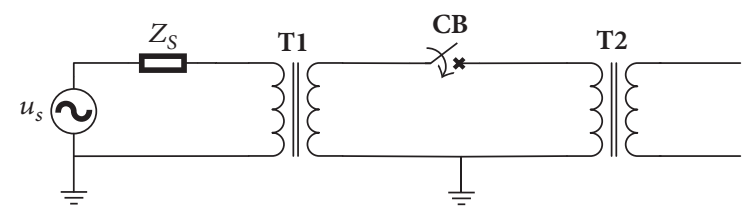

FIgURE 1: Transformers connected in series.

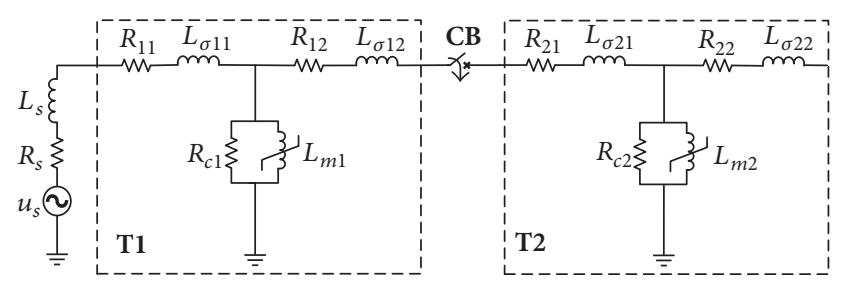

FIGURE 2: Equivalent circuit of series transformers.

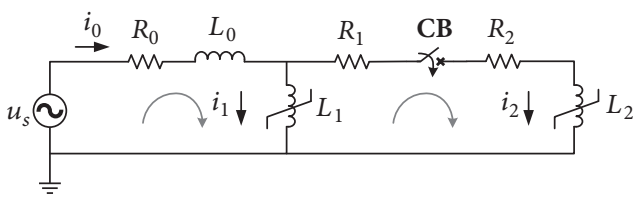

FIGURE 3: Simplified circuit of series transformers.

$L_{0}=L_{S}, L_{1}=L_{m 1}$, and $L_{2}=L_{m 2}$. Assume the source voltage varies sinusoidally with time; that is, $u_{s}=U_{m} \sin (\omega t+\varphi)$, where $U_{m}$ and $\varphi$ represent the amplitude and phase angle, respectively. The CB is closed at $t=0 \mathrm{~s}$.

The nonlinear characteristics of the iron core can be modeled using a piecewise linear inductance with two different slopes $[16,17]$. However, the magnetizing inductance is assumed to be linear to simplify the analysis [13]. The purpose of the study is to qualitatively understand the relationship between the flux linkages and inrush currents for series transformers. Equation (1) can be obtained by Kirchhoff's voltage law and Kirchhoff's current law:

$$
\begin{aligned}
U_{m} \sin (\omega t+\varphi) & =R_{0} i_{0}(t)+L_{0} \frac{d i_{0}(t)}{d t}+\frac{d \psi_{1}(t)}{d t} \\
\frac{d \psi_{1}(t)}{d t} & =\frac{d \psi_{2}(t)}{d t}+\left(R_{1}+R_{2}\right) i_{2} \\
i_{0}(t) & =i_{1}(t)+i_{2}(t)
\end{aligned}
$$

where $i_{0}(t), i_{1}(t)$, and $i_{2}(t)$ represent the branch currents in $L_{0}, L_{1}$, and $L_{2}$, respectively. $\psi_{1}(t)=L_{1} i_{1}(t)$ and $\psi_{2}(t)=$ $L_{2} i_{2}(t)$ represent the flux linkages of T1 and T2, respectively.

The Laplace transform of (1) is used to calculate the flux linkages in the frequency domain. Let $R_{3}=R_{1}+R_{2}$. Then the flux linkage expressions in the time domain are obtained using the inverse Laplace transform, as presented in

$$
\begin{gathered}
\psi_{1}(t)=-\frac{J}{2 C F L_{2}}\left\{e^{\tau_{1} t}[1\right. \\
\left.-\frac{A}{\sqrt{B^{2} / 4-A C}}\left(\frac{B}{2 A}+\frac{A K}{J}\right)\right]+e^{\tau_{2} t}[1
\end{gathered}
$$




$$
\begin{gathered}
\left.\left.+\frac{A}{\sqrt{B^{2} / 4-A C}}\left(\frac{B}{2 A}+\frac{A K}{J}\right)\right]\right\} \\
+\frac{\sqrt{R_{3}^{2}+\left(\omega L_{2}\right)^{2}}}{L_{2} F}\left[-G \sin \left(\omega t+\varphi+\theta_{1}\right)+B D \omega\right. \\
\left.\cdot \sin \left(\omega t+\varphi-\theta_{1}\right)\right] \\
\psi_{2}(t)=\frac{H}{2 F} \cdot\left\{e^{\tau_{1} t}\left[1-\frac{A}{\sqrt{B^{2} / 4-A C}}\left(\frac{B}{2 A}-\frac{A I}{H}\right)\right]\right. \\
\left.+e^{\tau_{2} t}\left[1+\frac{1}{\sqrt{B^{2} / 4-A C}}\left(\frac{B}{2 A}-\frac{A I}{H}\right)\right]\right\}+\frac{1}{F} \\
\cdot \omega \sqrt{(B D \omega)^{2}+G^{2}} \sin \left(\omega t+\varphi+\theta_{2}\right),
\end{gathered}
$$

where

$$
\begin{aligned}
& A=L_{0} L_{1}+L_{1} L_{2}+L_{0} L_{2} \\
& B=R_{0} L_{1}+R_{0} L_{2}+R_{3} L_{0}+R_{3} L_{1} \\
& C=R_{0} R_{3} \\
& D=L_{1} L_{2} U_{m} \\
& E=-R_{0} L_{2}\left[\psi_{1}\left(0_{-}\right)-\psi_{2}\left(0_{-}\right)\right] \\
& F=A^{2} \omega^{4}-2 A C \omega^{2}+B^{2} \omega^{2}+C^{2} \\
& G=A D \omega^{2}-C D \\
& H=\psi_{2}\left(0_{-}\right) F+\omega G \\
& I=E F+C(G \sin \varphi-B D \omega \cos \varphi) \\
& J=-C\left[\left(G R_{3}-B D \omega^{2} L_{2}\right) \sin \varphi\right. \\
& \left.+\left(G \omega L_{2}+B D \omega R_{3}\right) \cos \varphi\right]+E F R_{3}-C F L_{2} \psi_{2}\left(0_{-}\right) \\
& K=A C F R_{3} \psi_{2}\left(0_{-}\right)+E F\left(C L_{2}-B R_{3}\right)-\left(G L_{2}\right. \\
& \left.+B D R_{3}\right) \sin \varphi+\left[A G R_{3}+B D\left(B R_{3}-C L_{2}\right)\right] C \omega \\
& \cdot \cos \varphi \\
& \tau_{1}=\frac{-B+\sqrt{B^{2}-4 A C}}{2 A} \\
& \tau_{2}=\frac{-B-\sqrt{B^{2}-4 A C}}{2 A} \\
& \theta_{1}=\arctan \frac{\omega L_{2}}{R_{3}} \\
& \theta_{2}=\arctan \frac{-G}{B D \omega} \text {. }
\end{aligned}
$$

Here, $\tau_{1}$ and $\tau_{2}$ represent the decay coefficients of the DC components. $\psi_{1}\left(0_{-}\right)$and $\psi_{2}\left(0_{-}\right)$are the initial flux linkages of T1 and T2 at $t=0 \mathrm{~s}$, respectively. $\psi_{2}\left(0_{-}\right)$represents the residual flux linkage of the energized transformer T2. Therefore, the effect of residual flux can be included in (2).

Define $a_{1}, a_{2}, a_{3}, b_{1}, b_{2}, c_{1}$, and $c_{2}$ as in

$$
\begin{aligned}
& a_{1}=\frac{-G \sqrt{R_{3}{ }^{2}+\left(\omega L_{2}\right)^{2}}}{L_{2} F} \\
& a_{2}=\frac{B D \sqrt{R_{3}{ }^{2}+\left(\omega L_{2}\right)^{2}}}{L_{2} F} \\
& a_{3}=\frac{\omega \sqrt{(B D \omega)^{2}+G^{2}}}{F} \\
& b_{1}=-\frac{J}{2 C F L_{2}}\left[1-\frac{A}{\sqrt{B^{2} / 4-A C}}\left(\frac{B}{2 A}+\frac{A K}{J}\right)\right] \\
& b_{2}=\frac{H}{2 F}\left[1-\frac{A}{\sqrt{B^{2} / 4-A C}}\left(\frac{B}{2 A}-\frac{A I}{H}\right)\right] \\
& c_{1}=-\frac{J}{2 C F L_{2}}\left[1+\frac{A}{\sqrt{B^{2} / 4-A C}}\left(\frac{B}{2 A}+\frac{A K}{J}\right)\right] \\
& c_{2}=\frac{H}{2 F}\left[1+\frac{A}{\sqrt{B^{2} / 4-A C}}\left(\frac{B}{2 A}-\frac{A I}{H}\right)\right] .
\end{aligned}
$$

$a_{1}, a_{2}$, and $a_{3}$ represent the amplitude of the AC components, while $b_{1}, b_{2}, c_{1}$, and $c_{2}$ represent the amplitude of the DC components. Then, the transformer flux linkages are simplified as follows:

$$
\begin{aligned}
\psi_{1}(t)= & a_{1} \sin \left(\omega t+\varphi+\theta_{1}\right)+a_{2} \sin \left(\omega t+\varphi-\theta_{1}\right) \\
& +b_{1} e^{\tau_{1} t}+c_{1} e^{\tau_{2} t} \\
\psi_{2}(t)= & a_{3} \sin \left(\omega t+\varphi+\theta_{2}\right)+b_{2} e^{\tau_{1} t}+c_{2} e^{\tau_{2} t} .
\end{aligned}
$$

Both $\psi_{1}(t)$ and $\psi_{2}(t)$ consist of the AC component and decaying DC component. The two AC components of $\psi_{1}(t)$ can be simplified as an AC component, which is explained in detail in Section 3. The DC components consist of the $\tau_{1}$ component and $\tau_{2}$ component for both transformers.

\section{Transformer Flux Linkage Analysis}

3.1. AC Component of the Flux Linkages. Before the $\mathrm{CB}$ is closed, the transformer T1 is not saturated. Since the impedance of the magnetizing branch is much larger than the system impedance in this situation, the former divides most of the source voltage. Thus, the flux linkage of T1 is approximately equal to the integral of the source voltage, as expressed in

$$
\psi_{1}(t)=\int u_{s}(t) d t=\frac{U_{m}}{\omega} \cdot \sin \left(\omega t+\varphi-\frac{\pi}{2}\right) .
$$

Only the AC component is included in the flux linkage of T1 before the CB is closed. $\psi_{1}\left(0_{-}\right)=-U_{m} / \omega$ can be obtained from (6).

After the $\mathrm{CB}$ is closed, the $\mathrm{AC}$ components of $\mathrm{T} 1$ and T2 can be obtained from (2) and (5). The magnetizing 
inductance changes from several henries to several hundred henries for different types of transformers with different rated voltages, capacity, and so on. In comparison, the maximum winding resistance is several ohms, which means that $\omega L_{2} \gg$ $R_{3}$ and $\theta_{1} \approx \pi / 2$. Thus, $\psi_{1 \mathrm{AC}}(t)=a_{1} \sin \left(\omega t+\varphi+\theta_{1}\right)+$ $a_{2} \sin \left(\omega t+\varphi-\theta_{1}\right)$ can be written as

$$
\begin{gathered}
\psi_{1 \mathrm{AC}}(t)=\frac{D \sqrt{R_{3}^{2}+\left(\omega L_{2}\right)^{2}}\left(A \omega^{2}-C+B D \omega\right)}{L_{2}\left[\left(A \omega^{2}-C\right)^{2}+(B \omega)^{2}\right]} \\
\cdot \sin \left(\omega t+\varphi-\frac{\pi}{2}\right)=a_{4} \sin \left(\omega t+\varphi-\frac{\pi}{2}\right) .
\end{gathered}
$$

As for $\psi_{2 \mathrm{AC}}=a_{3} \sin \left(\omega t+\varphi+\theta_{2}\right), \theta_{2} \approx-\pi / 2$ can be obtained because $A \omega^{2}-C \gg B$. Similarly, it can be verified that $a_{4}$ and $a_{2}$ are approximately equal to $U_{m} / \omega$. Therefore, both $\psi_{1 \mathrm{AC}}$ and $\psi_{2 \mathrm{AC}}$ are approximately equal to the integral of the source voltage, that is, $U_{m} / \omega \cdot \sin (\omega t+\varphi-\pi / 2)$. The variation of $R$ and $L$ will not change this feature.

Series transformers typically differ in their capacity and voltage level. After being normalized to the primary side of $\mathrm{T} 1$, a group of equivalent parameters is taken as an example:

$$
\begin{aligned}
R_{S} & =10 \Omega \\
L_{S} & =0.3 \mathrm{H} \\
R_{11} & =2 \Omega \\
L_{m 1} & =67 \mathrm{H} \\
R_{12} & =2 \Omega \\
L_{m 2} & =130 \mathrm{H} \\
R_{21} & =3 \Omega \\
\omega & =100 \pi \mathrm{rad} / \mathrm{s} .
\end{aligned}
$$

The AC components of flux linkages for $\mathrm{T} 1$ and $\mathrm{T} 2$ can be obtained from (2) and (8), as shown in Figure 4. The base value is taken as the RMS value. The waveform is consistent with the analysis above.

3.2. Decaying DC Component. As shown in Figure 5, the decaying DC components of the flux linkages are also obtained from (2) and (8), where $\psi_{1 \mathrm{DC}}=b_{1} e^{\tau_{1} t^{t}}+c_{1} e^{\tau_{2} t}$ and $\psi_{2 \mathrm{DC}}=b_{2} e^{\tau_{1} t}+c_{2} e^{\tau_{2} t}$.

The DC components of the two flux linkages have opposite polarities. The amplitude of $\psi_{2 \mathrm{DC}}$ continues decaying from the initial maximum $\left(\left|\psi_{2 D_{\text {DC_max }}}\right|=1.405\right)$, while $\psi_{1 \mathrm{DC}}$ increases first and then decreases $\left(\left|\psi_{1 D_{\text {DC } \max }}\right|=0.364\right)$. The former has a peak value at the switching instant $(t=0 \mathrm{~s})$, and the latter has a peak value after several seconds $(t=9.4 \mathrm{~s})$. As shown in Figure 6, each flux linkage's DC component consists of two DC components with different decay coefficients $\left(\tau_{1}\right.$ component and $\tau_{2}$ component, resp.).

Although the decay coefficients of $\psi_{1 \mathrm{DC}}$ and $\psi_{2 \mathrm{DC}}$ are identical, their polarities and amplitudes are different. As a result, $\psi_{1 \mathrm{DC}}$ and $\psi_{2 \mathrm{DC}}$ change in different ways. Two positive DC components $\left(b_{2} e^{\tau_{1} t^{t}}\right.$ and $\left.c_{2} e^{\tau_{2} t}\right)$ exist in $\psi_{2 \mathrm{DC}}$. The superimposition of the two components is still positive and continually decays over time. In comparison, a positive
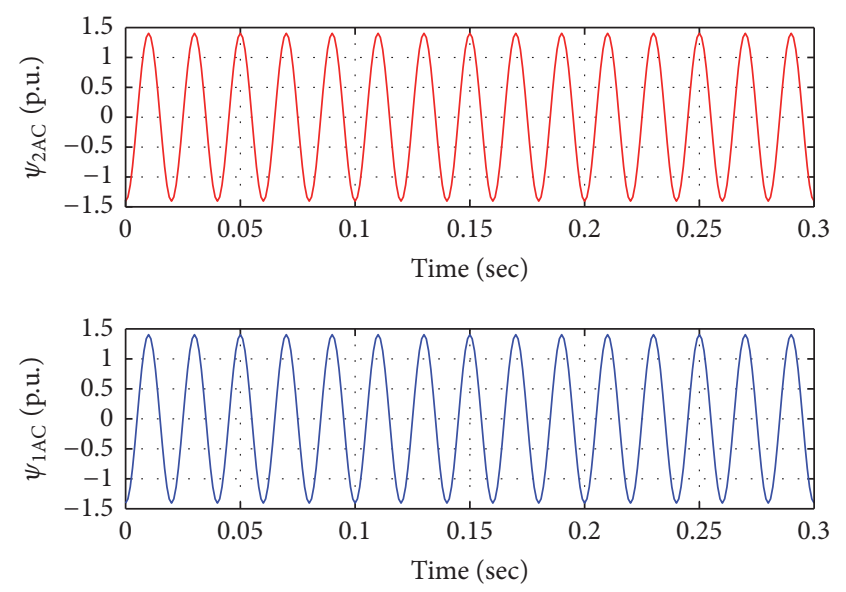

Figure 4: AC components of the flux linkages.
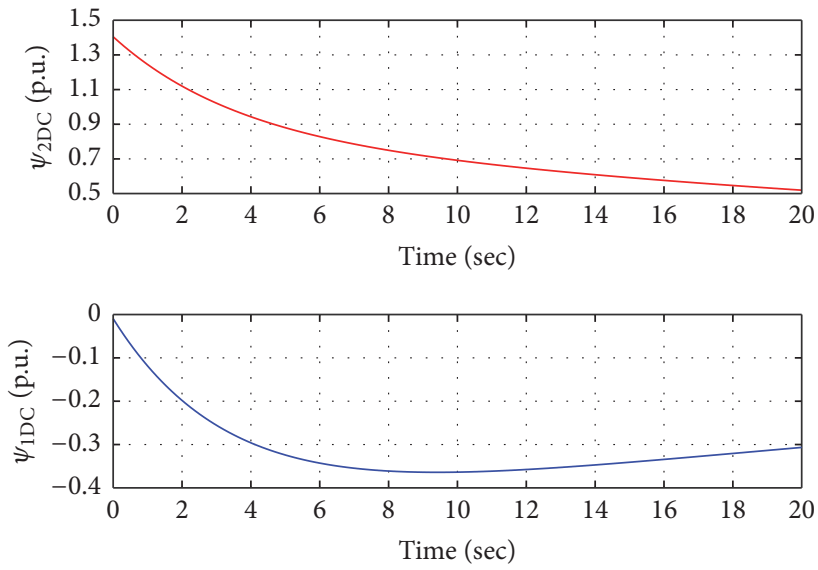

Figure 5: DC components of the flux linkages.

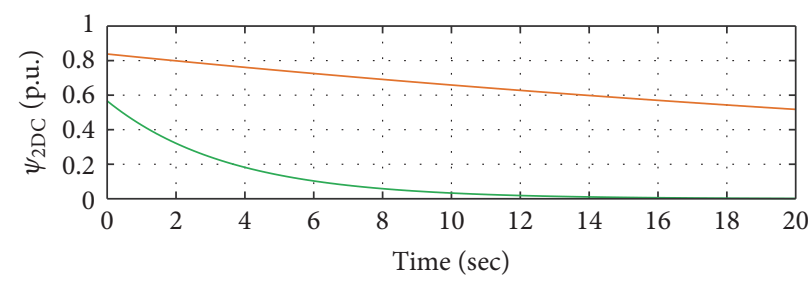

$-b_{2} e^{\tau_{1} t}$

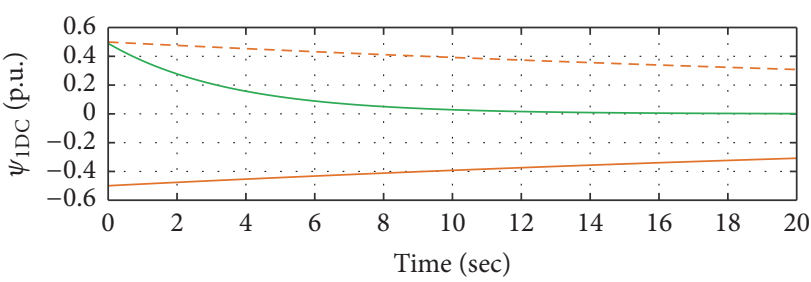

$\begin{array}{ll}- & b_{1} e^{\tau_{1} t} \\ - & c_{1} e^{\tau_{2} t} \\ --- & -b_{1} e^{\tau_{1} t}\end{array}$

Figure 6: $\tau_{1}$ and $\tau_{2}$ components of the flux linkages. 
TABle 1: Parameters of T1 and T2.

\begin{tabular}{cccccc}
\hline & Rated capacity (MVA) & Voltage ratio $(\mathrm{kV} / \mathrm{kV})$ & Winding connection & Knee voltage (p.u.) & Magnetizing reactance (p.u.) \\
\hline $\mathrm{T} 1$ & 31.5 & $220 / 6$ & $\mathrm{Y} / \mathrm{Y}$ & 1.12 & 0.14 \\
$\mathrm{~T} 2$ & 26 & $6.3 / 13.8$ & $\Delta / \mathrm{Y}$ & 1.15 & 0.3 \\
\hline
\end{tabular}

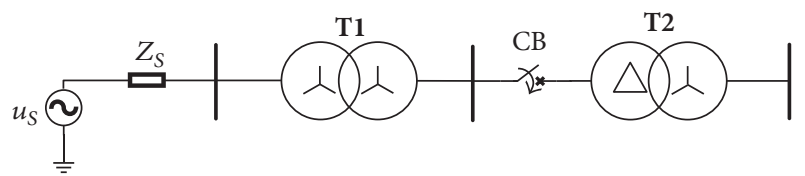

Figure 7: Series transformers simulation model.

component $c_{1} e^{\tau_{2} t}$ and a negative component $b_{1} e^{\tau_{1} t}$ exist in $\psi_{1 \mathrm{DC}}$. Since the negative component initially decays more slowly than the positive component, the amplitude of the superimposition component $\psi_{1 \mathrm{DC}}$ increases in the negative polarity. After several seconds, the negative component decays faster than the positive component; therefore, the amplitude of the superimposition component $\psi_{1 \mathrm{DC}}$ decreases in the negative polarity. Furthermore, the initial value of $\psi_{1 \mathrm{DC}}$ is approximately zero because the two components in opposite polarities have approximately equal amplitude at $t=0 \mathrm{~s}$.

3.3. Sympathetic Inrush Case. A transformer typically operates near the knee point of the saturation curve. Only a single AC component is included in the transformer flux linkage when the transformer operates in the steady state. However, the superimposition of the DC component makes the transformer operate far above the knee point. Then, the transformer is driven into saturation and the magnetizing inrush is generated. If a positive DC component is added to the $\mathrm{AC}$ component in the positive half cycle, then positive inrush is generated. If a negative DC component is added to the $\mathrm{AC}$ component in the negative half cycle, negative inrush will be generated. During sympathetic inrush, the DC components of the two transformers have opposite polarities, while the AC components have the same polarity. Therefore, the initial inrush and sympathetic inrush are alternately generated in the positive and negative half cycle of the AC component. Further explanation of the process can be found in Section 4.1. The physical mechanism of the sympathetic inrush for series transformers is similar to that for parallel transformers [13].

A sympathetic inrush simulation model of series transformers is constructed as Figure 7 in Power Systems Computer Aided Design (PSCAD) according to a real maloperation case in China. The system parameters are $U_{S}=235 \mathrm{kV}$ (RMS value of $u_{s}$ ), $\omega=100 \pi \mathrm{rad} / \mathrm{s}$, and $Z_{S}=30+j 283 \Omega$. The parameters of T1 and T2 are listed in Table 1, where the magnetizing reactance represents the reactance of the iron core that is fully saturated.

In the simulation, the $\mathrm{CB}$ is closed at $t=0.5 \mathrm{~s}$. T2 is energized when $\mathrm{T} 1$ is in service. Taking Phase A as an example, the switching angle of Phase $\mathrm{A}$ is $0\left(\varphi_{\mathrm{A}}=0^{\circ}\right)$. The magnetizing inrush currents corresponding to the inrush phenomenon can be obtained from the differential currents of $\mathrm{T} 1$ and $\mathrm{T} 2$. The differential currents $I_{\mathrm{T} 1 d A}$ and $I_{\mathrm{T} 2 d A}$

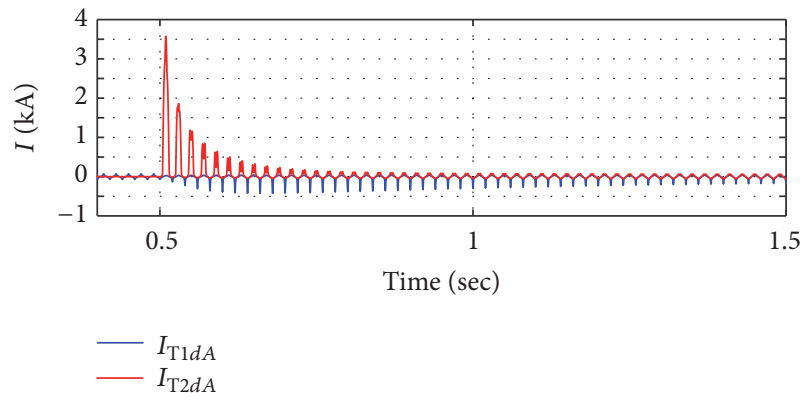

FIGURE 8: Initial inrush and sympathetic inrush of series transformers.

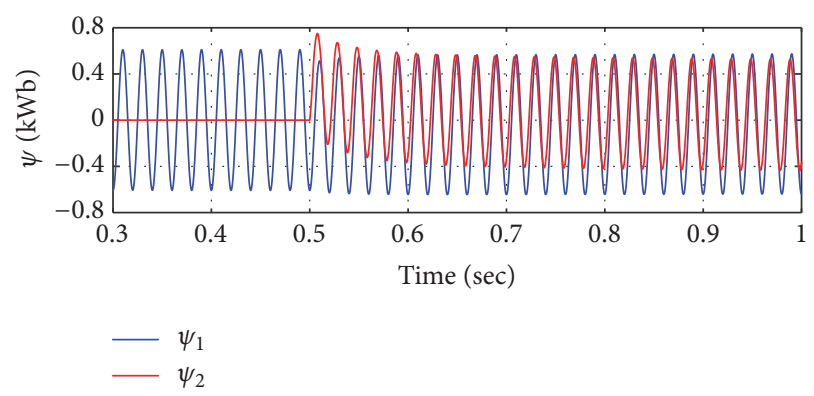

FIGURE 9: Flux linkages of series transformers.

are shown in Figure 8, which are normalized to the $6 \mathrm{kV}$ side. Positive initial inrush is generated in T2 and negative sympathetic inrush is generated in T1. Only the Phase A currents are shown because the inrush currents of Phase A are the largest. The variation of the flux linkages is shown in Figure 9. $\psi_{1}$ consists of the AC component and negative DC component, while $\psi_{2}$ consists of the AC component and positive DC component.

3.4. Interaction between the Series Transformers. If there is a single in-service transformer in the power system, only an AC component will be included in the transformer flux linkage. $\psi_{1 D C}$ is generated due to the other energized transformer. Thus, it is the interaction between the series transformers that generates the sympathetic inrush.

The flux linkage of a single energized transformer $\psi_{2}(t)_{s g}$ can also be derived in a similar way to $(2)$ :

$$
\begin{aligned}
\psi_{2}(t)_{s g} & \frac{L_{2} U_{m} \sin \left(\omega t+\varphi-\theta_{3}\right)}{\sqrt{\left(R_{4}\right)^{2}+\left(\omega L_{3}\right)^{2}}} \\
& +\left[\psi_{2}\left(0_{-}\right)-\frac{L_{2} U_{m} \sin \left(\varphi-\theta_{3}\right)}{\sqrt{\left(R_{4}\right)^{2}+\left(\omega L_{3}\right)^{2}}}\right] e^{\left(-R_{4} / L_{3}\right) t},
\end{aligned}
$$

where $R_{4}=R_{0}+R_{2}, L_{3}=L_{0}+L_{2}$, and $\theta_{3}=\arctan \left(\omega L_{3} / R_{4}\right)$. 


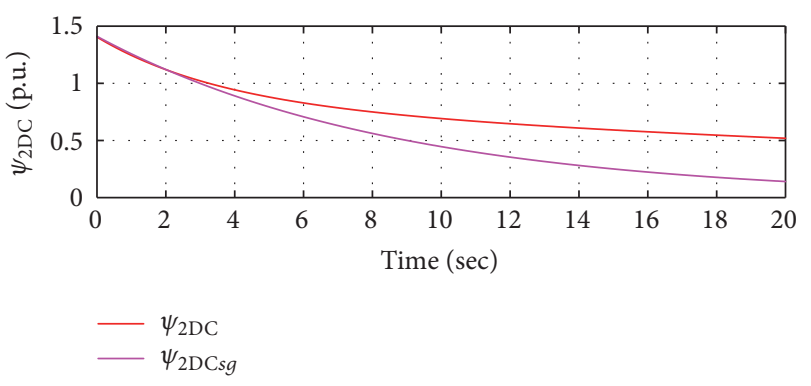

FIGURE 10: DC component of the energized transformer.

An AC component $\psi_{2 \mathrm{AC} s g}$ and a DC component $\psi_{2 \mathrm{DC} s}$ are included in the flux linkage. $\theta_{3} \approx-\pi / 2$ can be obtained, and $\psi_{2 \mathrm{ACs} g}$ is from the sinusoidal source voltage. It can be seen from (2) and (9) that the in-service transformer changes the decay coefficient of the DC component and increases a DC component to the flux linkage of the energized transformer. $\psi_{2 \mathrm{DC} s g}$ can be obtained from (8) and (9), as shown in Figure 10.

$\psi_{2 \mathrm{DC}}$ for series transformers is also shown in Figure 10 as a comparison. $\psi_{2 \mathrm{DC}}$ decays more slowly than $\psi_{2 \mathrm{DC} s g}$. As a result, the initial inrush decays more slowly due to the inservice transformer.

\section{Effect of Transformer Saturation on Inrush Currents}

Although the linear magnetizing inductance assumption is made to simplify the transformer flux linkage analysis above, the magnetizing inductance of the saturated transformer is actually nonlinear. The magnetic characteristics of the transformer are typically represented using the piecewise lines. The magnetizing inductance will significantly decrease if the transformer is driven into saturation. In this section, the flux linkages of saturated transformers are analyzed to investigate the effect of transformer saturation.

4.1. Variation of Magnetizing Inductance during Sympathetic Inrush. The piecewise lines representing the magnetizing characteristics are illustrated in Figure 11(a). The magnetizing inductance below the knee point (nonsaturation zone) is $L_{\text {non }}$, and that above the knee point (saturation zone) is $L_{\text {sat }}$. Since the equivalent inductance around the knee point varies dramatically, $L_{\text {non }}$ is much larger than $L_{\text {sat }}$. As shown in Figure 11(a), the addition of the DC components to the AC components during one cycle of the flux linkages can be used to explain the variation of the magnetizing inductance further. As analyzed in Section 3, the DC components of the two transformers have opposite polarities, and the $\mathrm{AC}$ components are approximately equal.

(1) Before $t_{1}$, positive $\psi_{2 \mathrm{AC}}$ and $\psi_{2 \mathrm{DC}}$ are added together, but $\psi_{2 \mathrm{AC}}$ is small, and thus $\psi_{2}=\psi_{2 \mathrm{AC}}+\psi_{2 \mathrm{DC}}$ is below the knee point. Positive $\psi_{1 \mathrm{AC}}$ and negative $\psi_{1 \mathrm{DC}}$ also cause $\psi_{1}=$ $\psi_{1 \mathrm{AC}}+\psi_{1 \mathrm{DC}}$ to be below the knee point. Therefore, T1 and T2 are not saturated and the magnetizing inductance of each transformer is $L_{\text {non }}$. (2) As the instantaneous value of $\psi_{\mathrm{AC}}$ increases to the peak value during $t_{1}-t_{2}, \psi_{2}$ is above the knee point. T2 is driven into saturation while the positive $\psi_{1 \mathrm{AC}}$ and negative $\psi_{1 \mathrm{DC}}$ keep $\psi_{1}$ below the knee point. Therefore, the magnetizing inductance of T1 is $L_{\text {non }}$, while that of T2 is $L_{\text {sat }}$. (3) As the instantaneous value of $\psi_{\mathrm{AC}}$ decreases from $t_{2}, \mathrm{~T} 2$ enters the nonsaturation zone. As $\psi_{\mathrm{AC}}$ decreases further, T1 is driven into saturation in the negative half cycle in a similar way.

Therefore, T1 and T2 (T1/T2) go through four stages sequentially in each cycle during sympathetic inrush: nonsaturation/nonsaturation, nonsaturation/saturation, nonsaturation/nonsaturation, and saturation/nonsaturation. The corresponding four stages are for the periods $0-t_{1}, t_{1}-t_{2}, t_{2}-t_{4}$, and $t_{4}-t_{5}$. In the period $t_{5}-t_{6}, \mathrm{~T} 1$ and T2 keep unsaturated to the next cycle. The magnetizing inductance values will change with different stages, as shown in Figure 11(b). When the sympathetic inrush is generated, the equivalent magnetizing inductance of the in-service transformer is alternately presented at $L_{\text {non }}$ and $L_{\text {sat. }}$. The same effect occurs for the magnetizing inductance of the energized transformer when the initial inrush is generated. In addition, $L_{\text {non }}$ and $L_{\text {sat }}$ of the two transformers are actually different. $L_{\text {non } 1}$ and $L_{\text {sat1 }}$ are the magnetizing inductance of T1 while $L_{\text {non2 }}$ and $L_{\text {sat2 }}$ are the magnetizing inductance of $\mathrm{T} 2$.

For the AC components, the decrease of the magnetizing inductance will not change the feature of $\psi_{1 \mathrm{AC}}$ and $\psi_{2 \mathrm{AC}}$ because the conditions $\omega L_{2} \gg R_{3}$ and $A \omega^{2}-C \gg B$ still hold true, even if the magnetizing inductance decreases. Therefore, $\psi_{1 \mathrm{AC}}$ and $\psi_{2 \mathrm{AC}}$ are both approximately equal to $U_{m} / \omega \cdot \sin (\omega t+\varphi-\pi / 2)$. The saturation of the transformers has a slight impact on the AC components.

For the DC components, the magnetizing inductance is assumed to be linear in the DC component analysis in Section 3. This assumption can be explained further as follows. When the CB is closed, the DC component of the flux linkage is generated to prevent the flux linkage from changing discretely. At the switching instant, the magnetizing inductance is $L_{\text {non }}$, in the period $0-t_{1}$. Therefore, the variation feature of the DC component is determined predominantly by $L_{\text {non }}$ at the switching instant. The main characteristic of the flux linkage will not change even if the transformer is driven into saturated saturation. The reason is that the circuit is no longer forced to change and there is no new DC component generated to prevent a discrete change in the flux linkage. The effect of transformer saturation is to change the amplitude and decay rate to some degree.

Further research is implemented to analyze the influence of the decrease of magnetizing inductance on the DC components.

4.2. DC Components of Flux Linkages When T2 Is Saturated. When T2 is saturated at the $t_{1}-t_{2}$ stage, $L_{m 2}$ is reduced to $L_{\text {sat2 }}$, while $L_{m 1}=L_{\text {non } 1}$. The DC components of the flux linkages are obtained by taking a smaller $L_{m 2}$ into (2), where $L_{\text {sat2 } 2}=60 \mathrm{H}$ or $20 \mathrm{H}$. Although the stage of $L_{m 2}=L_{\text {sat } 2}$ is only a short period in a cycle, the effect is analyzed qualitatively using $L_{\text {sat2 }}$ in the entire decay process. The DC components of the flux linkages are shown in Figure 12. $\psi_{2 \mathrm{DC}}$ decays more quickly in the main decay process and $\psi_{1 \mathrm{DC}}$ has an 


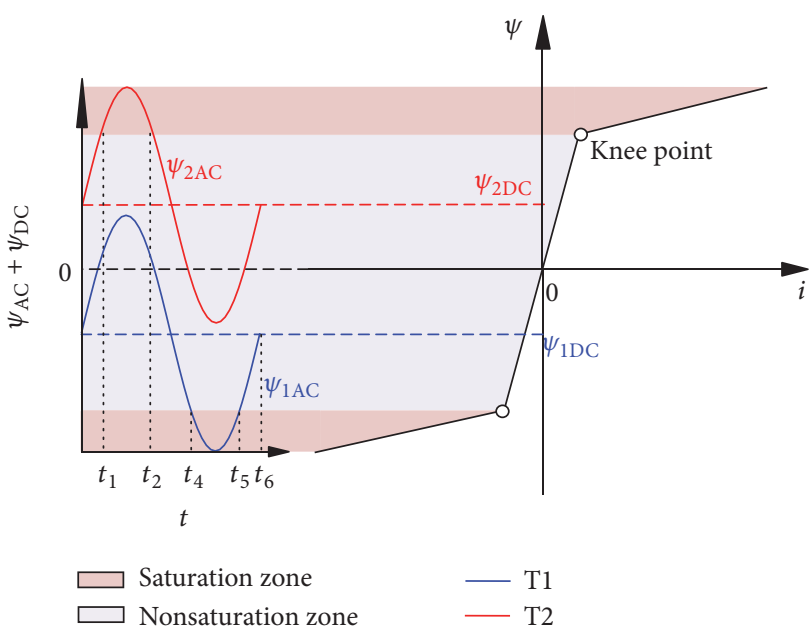

(a)

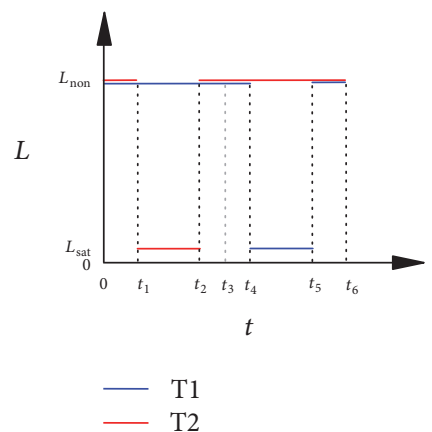

(b)

FIgURE 11: (a) The flux linkages and piecewise linear magnetization curve. (b) The equivalent magnetizing inductance during sympathetic inrush.

TABLE 2: Decay coefficients varying with $L_{m 2}$.

\begin{tabular}{lccc}
\hline$L_{m 2}(\mathrm{H})$ & 130 & 60 & 20 \\
\hline$\tau_{1}$ & -0.0241 & -0.0349 & -0.0455 \\
$\tau_{2}$ & -0.2839 & -0.4236 & -0.9650 \\
\hline
\end{tabular}

earlier and larger peak value with the decrease in $L_{m 2}$. The reason is that the faster decaying component of $\psi_{1 \mathrm{DC}}\left(\tau_{2}\right.$ component) decays much faster and the amplitude of each component of $\psi_{1 \mathrm{DC}}\left(\tau_{1}\right.$ and $\tau_{2}$ components) increases. The $\tau_{1}$ and $\tau_{2}$ components under different $L_{m 2}$ values are shown in Figure 13, and the decay coefficients are listed in Table 2. $\left|b_{1}\right|,\left|c_{1}\right|$, and $\left|c_{2}\right|$ increase, while $\left|b_{2}\right|$ decreases with decreasing $L_{m 2} \cdot\left|\tau_{1}\right|$ and $\left|\tau_{2}\right|$ increase with decreasing $L_{m 2}$.

As a result, the initial inrush and sympathetic inrush are influenced. The initial inrush will decay more quickly, and the sympathetic inrush will be strengthened.

\subsection{Components of Flux Linkages When T1 Is Saturated.} When T1 is saturated at the $t_{4}-t_{5}$ stage, $L_{m 1}$ is reduced to $L_{\text {sat1 }}$, while $L_{m 2}=L_{\text {non2 }}$. The DC components of the flux linkages are then obtained by taking a smaller $L_{m 1}$ into (2), where $L_{\text {sat1 }}$ $=30 \mathrm{H}$ or $10 \mathrm{H}$. The DC components are shown in Figure 14 . $\psi_{2 \mathrm{DC}}$ decays more slowly, and $\psi_{1 \mathrm{DC}}$ decreases with decreasing $L_{m 1}$. When $L_{m 1}$ decreases to $10 \mathrm{H}, \psi_{1 \mathrm{DC}}$ is too small to lead to the sympathetic inrush. $\tau_{1}$ and $\tau_{2}$ components of the flux linkages are shown in Figure 15. $\left|b_{1}\right|,\left|c_{1}\right|$, and $\left|c_{2}\right|$ decrease while $\left|b_{2}\right|$ increases with decreasing $L_{m 1}$. As listed in Table 3, $\left|\tau_{1}\right|$ and $\left|\tau_{2}\right|$ increase with decreasing $L_{m 1}$. As a result, the decay rate of each component increases. $\psi_{2 \mathrm{DC}}$ decays more slowly with decreasing $L_{m 1}$ because the more slowly decaying component of $\psi_{2 \mathrm{DC}}\left(\tau_{1}\right.$ component) has a larger amplitude.

In regard to the inrush currents of the transformers, the sympathetic inrush is weakened and the initial inrush decays more slowly due to the saturation of $\mathrm{T} 1$.

In conclusion, the series transformers interact with each other due to the transformer saturation. The initial inrush

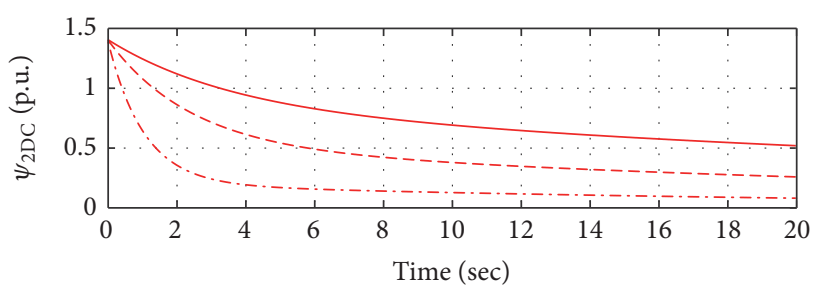

$-L_{m 1}=67 \mathrm{H}, L_{m 2}=130 \mathrm{H}$

-- $L_{m 1}=67 \mathrm{H}, L_{m 2}=60 \mathrm{H}$

-.- $L_{m 1}=67 \mathrm{H}, L_{m 2}=20 \mathrm{H}$

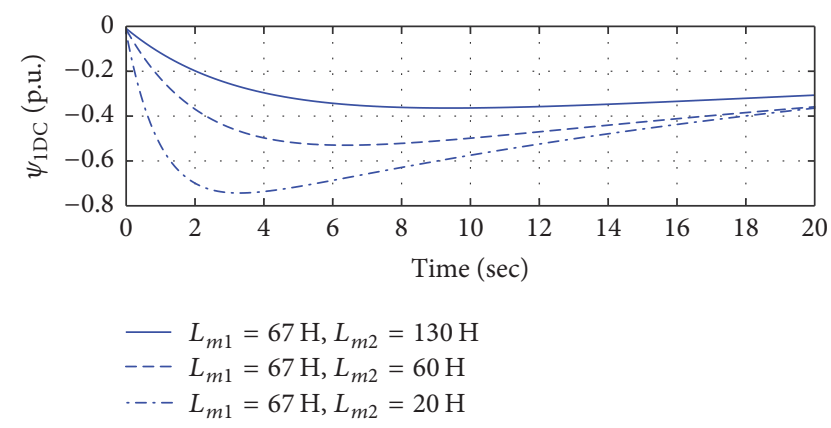

FIGURE 12: DC components of the flux linkages under different $L_{m 2}$.

decays more quickly due to the saturation of the energized transformer, and the sympathetic inrush is weakened due to saturation of the in-service transformer. The saturation of the transformer resists further saturation, which can be thought of as a self-regulating mechanism. On the other hand, the initial inrush decays more slowly due to saturation of the in-service transformer, and the sympathetic inrush is strengthened due to saturation of the energized transformer. The saturation of one transformer strengthens the other transformer's saturation, which can be explained in terms of the energy balance of the two transformers. 


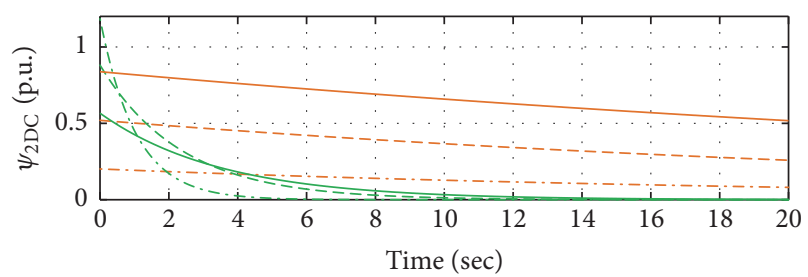

$-L_{m 1}=67 \mathrm{H}, L_{m 2}=130 \mathrm{H}-b_{2} e^{\tau_{1} t}$ --- $L_{m 1}=67 \mathrm{H}, L_{m 2}=60 \mathrm{H} \quad-c_{2} e^{\tau_{2} t}$ ... $L_{m 1}=67 \mathrm{H}, L_{m 2}=20 \mathrm{H}$

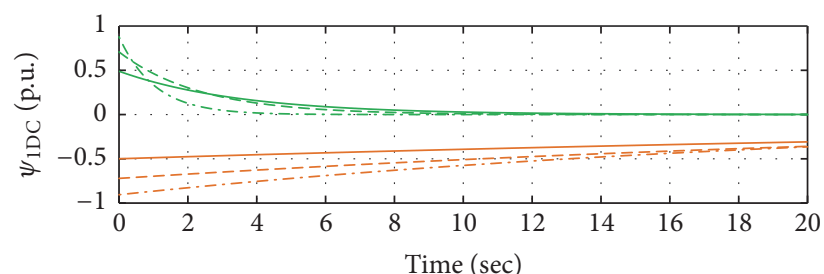

$-L_{m 1}=67 \mathrm{H}, L_{m 2}=130 \mathrm{H}-b_{1} e^{\tau_{1} t}$

$--L_{m 1}=67 \mathrm{H}, L_{m 2}=60 \mathrm{H} \quad-c_{1} e^{\tau_{2} t}$

-.-- $L_{m 1}=67 \mathrm{H}, L_{m 2}=20 \mathrm{H}$

FIGURE 13: $\tau_{1}$ and $\tau_{2}$ components of the flux linkages under different $L_{m 2}$.
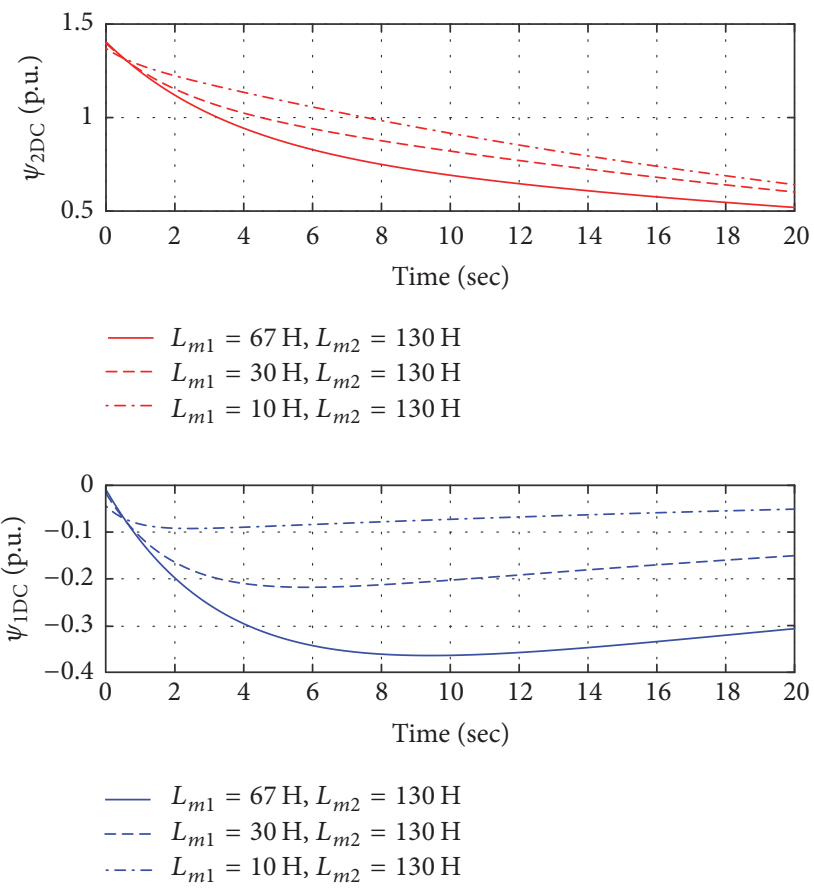

FIGURE 14: DC components of the flux linkages under different $L_{m 1}$.

\section{Influencing Factors of Sympathetic Inrush}

External conditions for the series transformers that have been connected to the power system vary greatly during sympathetic inrush. The switching angle and residual flux of the energized transformer vary widely, and their values depend on the switching time of the CB. Moreover, the system impedance and the load vary greatly under different
TABLE 3: Decay coefficients varying with $L_{m 1}$.

\begin{tabular}{lccc}
\hline$L_{m 1}(\mathrm{H})$ & 67 & 30 & 10 \\
\hline$\tau_{1}$ & -0.0241 & -0.0308 & -0.0356 \\
$\tau_{2}$ & -0.2839 & -0.4939 & -1.2546 \\
\hline
\end{tabular}

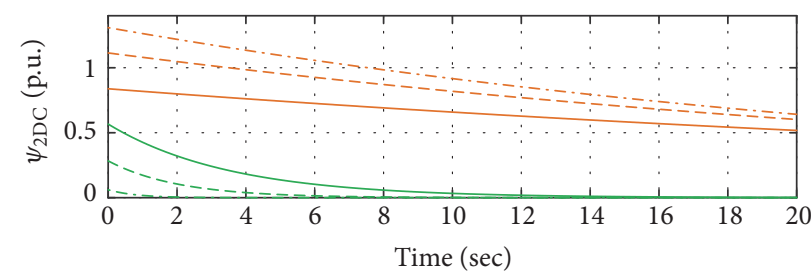

$$
\begin{aligned}
-L_{m 1} & =67 \mathrm{H}, L_{m 2}=130 \mathrm{H} \quad-b_{2} e^{\tau_{1} t} \\
---L_{m 1} & =30 \mathrm{H}, L_{m 2}=130 \mathrm{H} \quad-c_{2} e^{\tau_{2} t} \\
---L_{m 1} & =10 \mathrm{H}, L_{m 2}=130 \mathrm{H}
\end{aligned}
$$

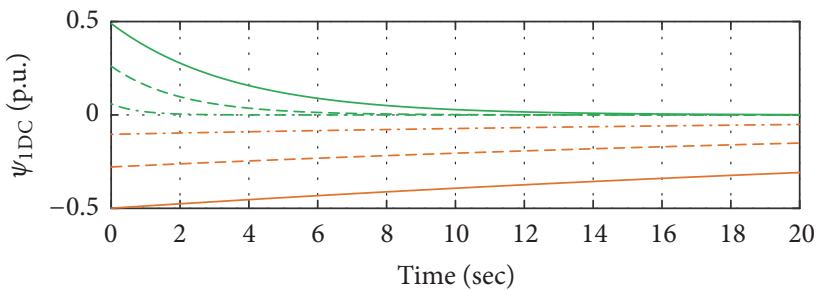

$$
\begin{aligned}
-L_{m 1} & =67 \mathrm{H}, L_{m 2}=130 \mathrm{H} \quad-b_{1} e^{\tau_{1} t} \\
---L_{m 1} & =30 \mathrm{H}, L_{m 2}=130 \mathrm{H} \quad-c_{1} e^{\tau_{2} t} \\
---L_{m 1} & =10 \mathrm{H}, L_{m 2}=130 \mathrm{H}
\end{aligned}
$$

FIGURE 15: $\tau_{1}$ and $\tau_{2}$ components of the flux linkages under different $L_{m 1}$.

operating conditions of the power system. Therefore, their impacts on the sympathetic inrush are investigated in this section.

5.1. Switching Angle. For a single energized transformer without residual flux, the flux linkage has a maximum DC component when the $\mathrm{CB}$ is closed at $\varphi=0^{\circ}$ because the prospective flux linkage is at the maximum, and the existing flux linkage cannot be changed suddenly. The flux linkage has a minimum DC component when the CB is closed at $\varphi=90^{\circ}$.

Similarly, the largest initial and sympathetic inrush currents are generated at $\varphi=0^{\circ}$ and the smallest are generated at $\varphi=90^{\circ}$ without residual flux. By taking different $\varphi$ in (2), the DC components of the flux linkages are obtained and are shown in Figure 16. $\left|b_{1}\right|,\left|b_{2}\right|,\left|c_{1}\right|$, and $\left|c_{2}\right|$ all decrease when $\varphi$ varies from $0^{\circ}$ to $90^{\circ}$. Therefore, the magnetizing inrush and sympathetic inrush are both weakened as $\varphi$ increases and will cease at $\varphi=90^{\circ}$.

A simulation model (shown in Figure 7) is constructed in PSCAD. The inrush currents can be represented by the differential currents, as shown in Figure 17, which are normalized to the $6 \mathrm{kV}$ voltage side. A Y $/ \mathrm{Y}$ energized transformer is used in this case instead of the $\Delta / \mathrm{Y}$ transformer because the variation feature under different switching angles can be observed more clearly using a Y/Y transformer. It is observed that the variation of the inrush currents is the same as the variation of the DC components of the flux linkages. 

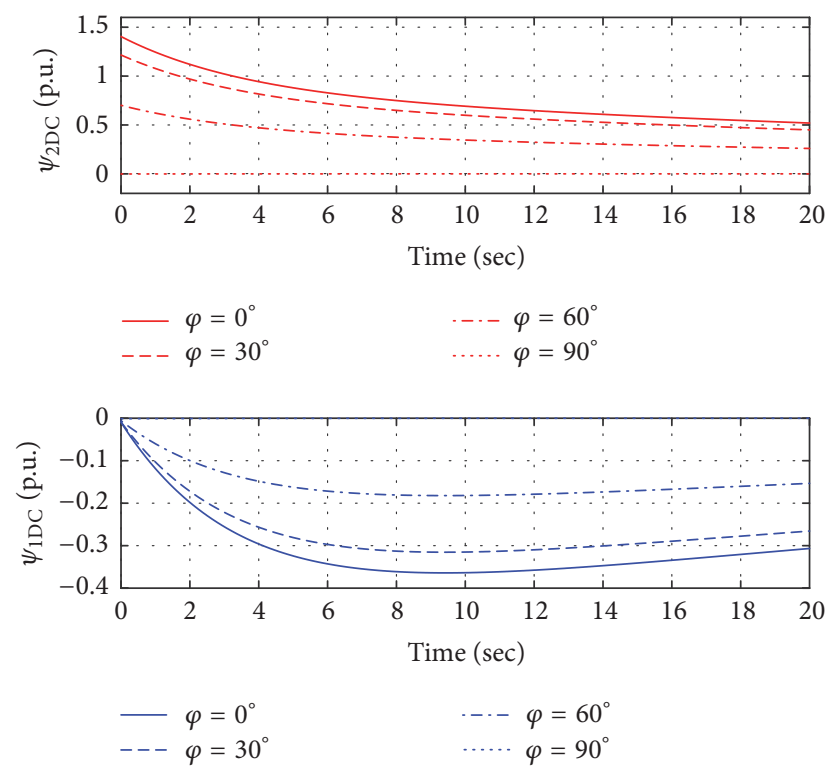

FIGURE 16: Variation of the DC components of the flux linkages with the switching angle.

5.2. Residual Flux. The residual flux of the energized transformer is another important factor that influences the inrush phenomenon. The difference between the residual flux linkage and prospective flux linkage of the energized transformer determines the amplitude of the initial inrush and sympathetic inrush. If the difference is large, the initial inrush and sympathetic inrush are also large. As shown in Figure 18, the DC components of flux linkages vary with the residual flux $\left(\varphi=0^{\circ}\right)$. When the $\mathrm{CB}$ is closed at $\varphi$ $=0^{\circ}$, the prospective flux linkage is approximately equal to $-U_{m} / \omega$. The DC components are the largest when the residual flux is $U_{m} / \omega$ and are zero when the residual flux is $-U_{m} / \omega$. A simulation case is conducted in Real Time Digital Simulator (RTDS) to further demonstrate the analysis. The inrush currents are shown in Figure 19.

5.3. System Impedance. The system impedance $Z_{S}=\mid R_{S}+$ $j \omega L_{S} \mid$ also has a significant effect on the inrush currents. The DC components of the flux linkages are obtained from (2) and are shown in Figure 20. $\psi_{1 \mathrm{DC}}$ has larger and earlier peak values as $Z_{S}$ increases. A larger $Z_{S}$ is more beneficial for the generation of the sympathetic inrush. $\psi_{2 \mathrm{DC}}$ is smaller in the main decay process as $Z_{S}$ increases, particularly before $t=8 \mathrm{~s}$. The system impedance has a greater effect on the sympathetic inrush than the initial inrush.

The inrush currents varying with the system impedance by simulation conducted in PSCAD are shown in Figure 21. The larger $Z_{S}$ weakens the initial inrush and causes the sympathetic inrush to have a larger and earlier peak value, validating the theoretical analysis.

5.4. Load of the In-Service Transformer. The load of the inservice transformer is also an important factor, especially for series transformers. The load adds an impedance branch to the right side of $L_{1 \sigma}$. The added branch restrains the influence
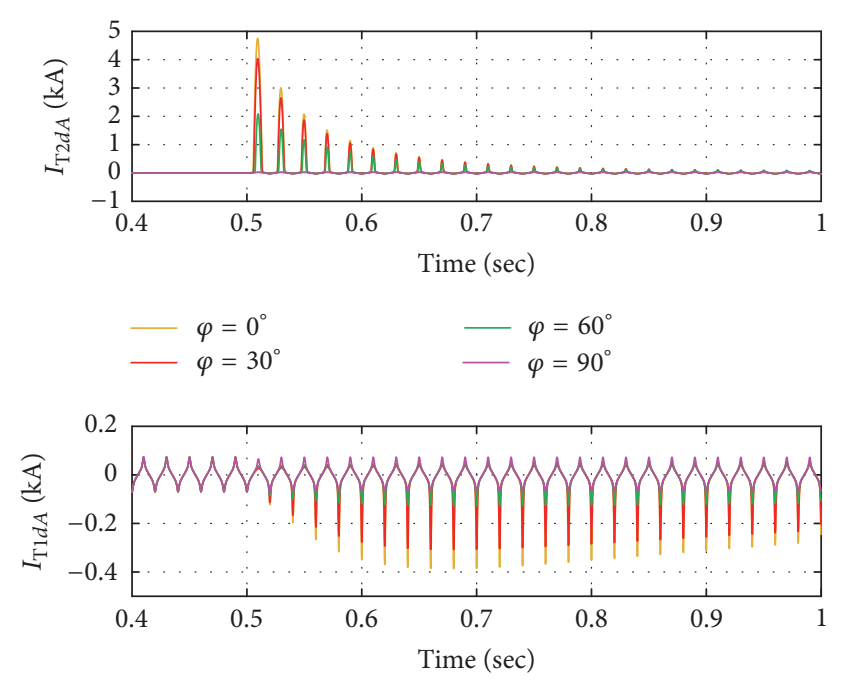

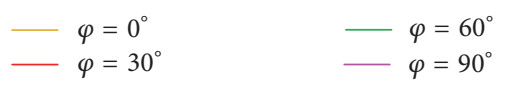

FIGURE 17: Variation of the initial inrush and sympathetic inrush with the switching angle.
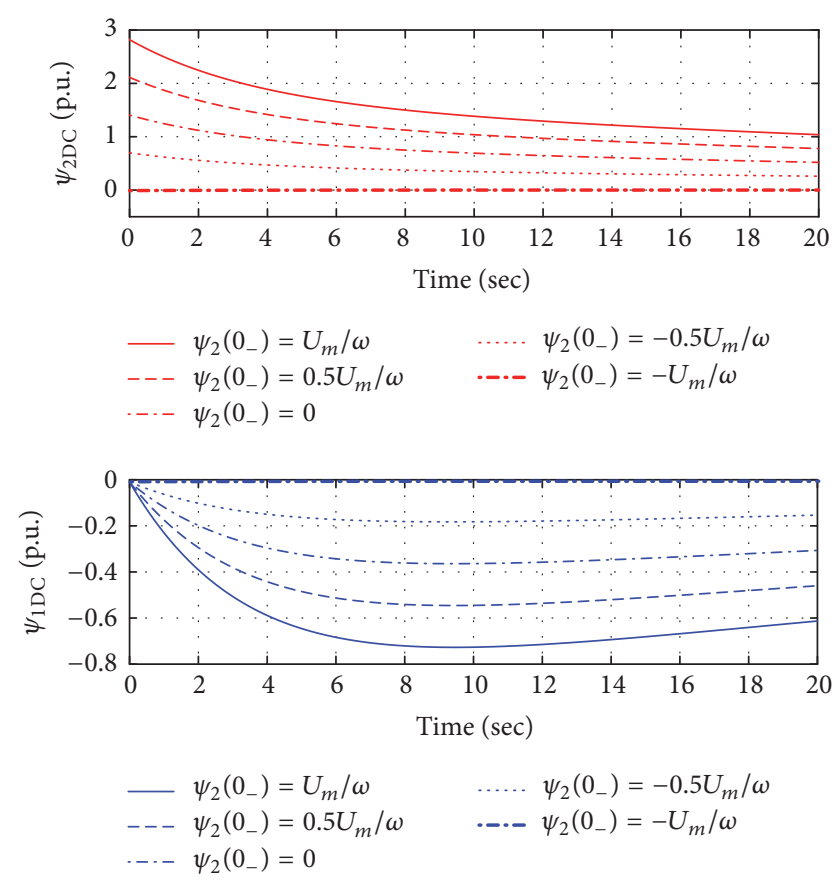

FIGURE 18: Variation of the DC components of the flux linkages with residual flux.

of the initial inrush on the in-service transformer. Although the flux linkage expressions including the load parameter have not been obtained, a simulation can be conducted to analyze the effect of the load. As shown in Figure 22, the initial inrush and sympathetic inrush decrease with increasing load, and the sympathetic inrush may disappear under a heavy load.

In contrast, the maximum amplitude of the sympathetic inrush generated in the parallel transformers at $P_{L}=30 \mathrm{MW}$ 

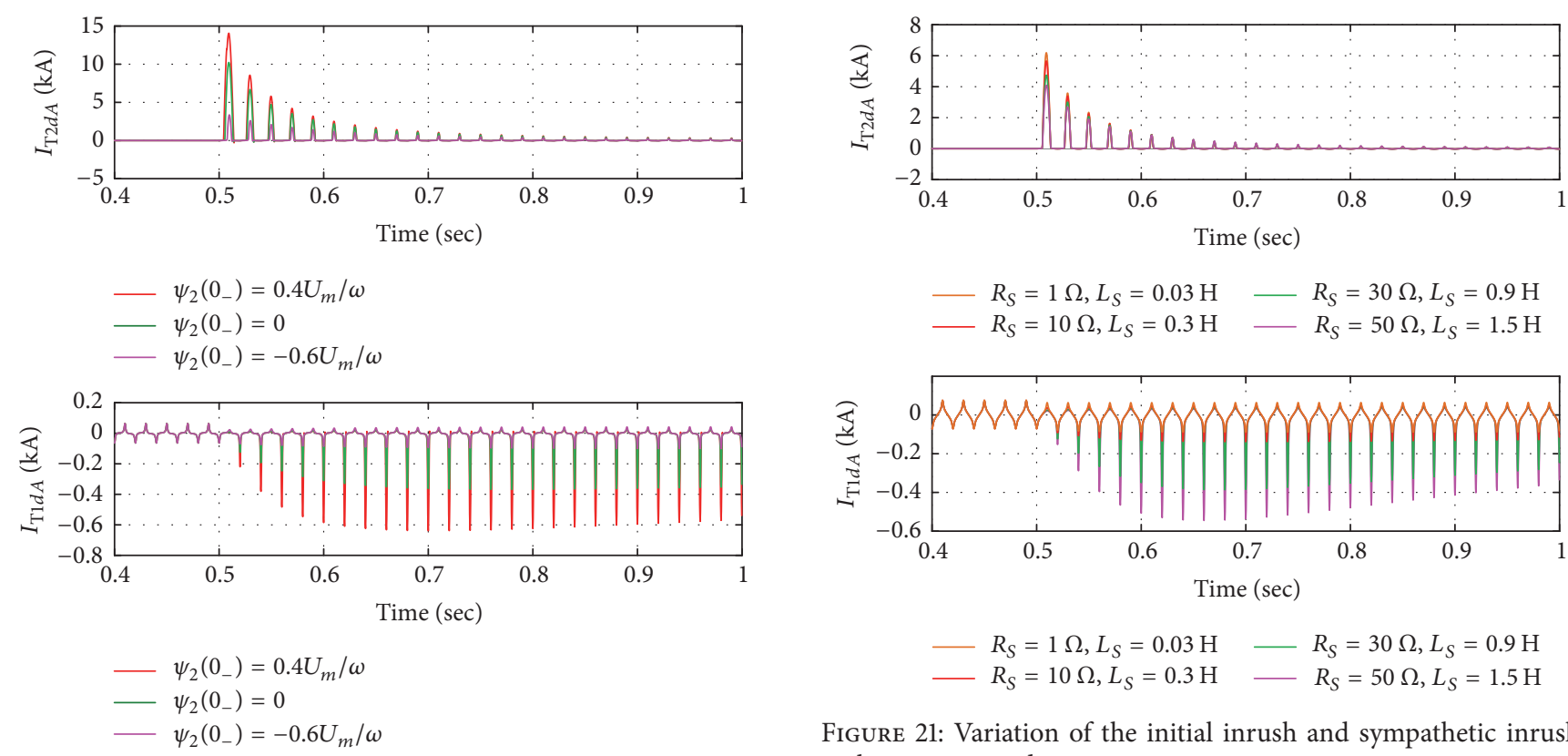

FIGURE 19: Variation of the initial inrush and sympathetic inrush with residual flux.
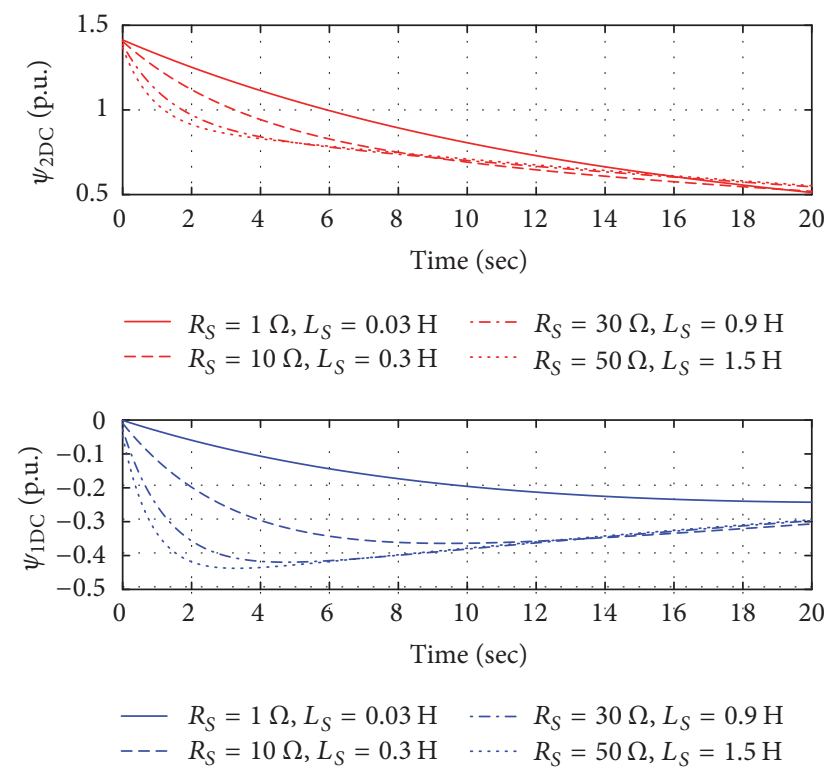

FIGURE 20: Variation of the DC components of the flux linkages with system impedance.

exhibits a $15 \%$ decrease relative to that at $P_{L}=0 \mathrm{MW}$. Here, the type of parallel transformers in the simulation is the same as T1. The results show that the influence of the load on the series transformers is more significant than that on the parallel transformers.

\section{Conclusion}

This paper presents a thorough study of the sympathetic inrush for series transformers. Flux linkage expressions of series transformers, including the switching angle, residual

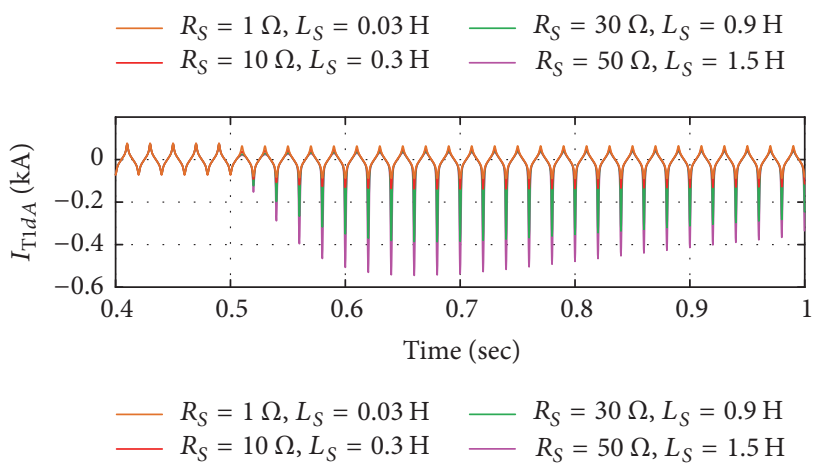

FIGURE 21: Variation of the initial inrush and sympathetic inrush with system impedance.
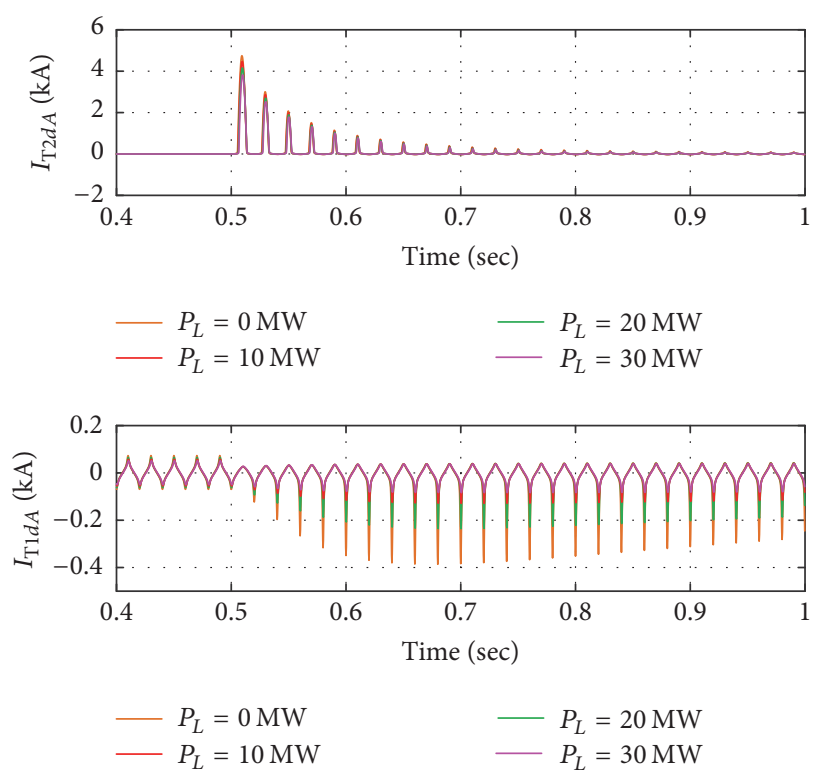

FIGURE 22: Variation of the initial inrush and sympathetic inrush with the load.

flux, and system impedance factors, are derived using the Laplace transform. Flux linkages of series transformers consist of the AC and DC components when the sympathetic inrush occurs. The series transformers interact with each other during the sympathetic inrush. Saturation of each transformer resists further self-saturation and strengthens the other transformer's saturation.

The influencing factors of sympathetic inrush for series transformers, including the switching angle, residual flux, and system impedance, are analyzed and validated. The smaller switching angle $\left(0^{\circ}-90^{\circ}\right)$, larger impedance, and lighter load are more beneficial for the generation of the 
sympathetic inrush. If the difference between the residual flux in the energized transformer and the integral of the energizing voltage is large, the initial inrush and sympathetic inrush are also large.

\section{Conflicts of Interest}

The authors declare that there are no conflicts of interest regarding the publication of this article.

\section{References}

[1] M. Steurer and K. Fröhlich, "The impact of inrush currents on the mechanical stress of high voltage power transformer coils," IEEE Transactions on Power Delivery, vol. 17, no. 1, pp. 155-160, 2002.

[2] M. Nagpal, T. G. Martinich, A. Moshref, K. Morison, and P. Kundur, "Assessing and limiting impact of transformer inrush current on power quality," IEEE Transactions on Power Delivery, vol. 21, no. 2, pp. 890-896, 2006.

[3] J. Peng, H. Li, Z. Wang, F. Ghassemi, and P. Jarman, "Influence of sympathetic inrush on voltage dips caused by transformer energisation," IET Generation, Transmission \& Distribution, vol. 7, no. 11, pp. 1173-1184, 2013.

[4] V. Vaddeboina, G. Taylor, and C. Proudfoot, "Switching large transformers on weak transmission networks-a real time case study," in Proceedings of the 47th International Universities Power Engineering Conference (UPEC '12), September 2012.

[5] X. Qi, X. Yin, and Z. Zhang, "Sympathetic inrush current in a transformer and a method for its identification," IEEJ Transactions on Electrical and Electronic Engineering, vol. 11, no. 4, pp. 442-450, 2016.

[6] H. S. Bronzeado, P. B. Brogan, and R. Yacamini, "Harmonic analysis of transient currents during sympathetic interaction," IEEE Transactions on Power Systems, vol. 11, no. 4, pp. 20512056, 1996.

[7] H. Bronzeado and R. Yacamini, "Phenomenon of sympathetic interaction between transformers caused by inrush transients," IEE Proceedings - Science, Measurement and Technology, vol. 142, no. 4, pp. 323-329, 1995.

[8] X. Qi, X. Yin, Z. Zhang, D. Chen, Y. Wang, and F. Cai, "Study on the unusual misoperation of differential protection during transformer energization and its countermeasure," IEEE Transactions on Power Delivery, vol. 31, no. 5, pp. 1998-2007, 2016.

[9] F. Wang, X. Qi, Y. Wang et al., "A sympathetic inrush detection method based on on-line magnet flux calculation," in Proceedings of the 2014 International Conference on Power System Technology (POWERCON '14), pp. 700-704, October 2014.

[10] T. Zheng, J. Gu, S. F. Huang, F. Guo, and V. Terzija, "A new algorithm to avoid maloperation of transformer differential protection in substations with an inner bridge connection," IEEE Transactions on Power Delivery, vol. 27, no. 3, pp. 11781185, 2012.

[11] U. Rudez and R. Mihalic, "A reconstruction of the WAMSdetected transformer sympathetic inrush phenomenon," IEEE Transactions on Smart Grid.

[12] C. D. Hayward, "Prolonged inrush currents with parallel transformers affect differential relaying," Electrical Engineering, vol. 60, no. 12, pp. 1096-1101, 1941.
[13] U. Rudez and R. Mihalic, "Sympathetic inrush current phenomenon with loaded transformers," Electric Power Systems Research, vol. 138, pp. 3-10, 2016.

[14] P. Heretik, M. Kovac, A. Belan, V. Volcko, and M. Konicek, "Analytical analysis of transformer interaction caused by inrush current," in Proceedings of the 15th International Scientific Conference on Electric Power Engineering (EPE '14), pp. 23-28, Brno-Bystrc, Czech Republic, May 2014.

[15] A. Tokić, I. Uglešić, and G. Štumberger, "Simulations of transformer inrush current by using BDF-based numerical methods," Mathematical Problems in Engineering, vol. 2013, Article ID 215647, 10 pages, 2013.

[16] J. A. Martinez and B. A. Mork, "Transformer modeling for lowand mid-frequency transients-a review," IEEE Transactions on Power Delivery, vol. 20, no. 2, pp. 1625-1632, 2005.

[17] X. Zhang, "An efficient algorithm for transient calculation of the electric networks including magnetizing branches," Mathematical Problems in Engineering, vol. 2011, Article ID 479626, 11 pages, 2011. 


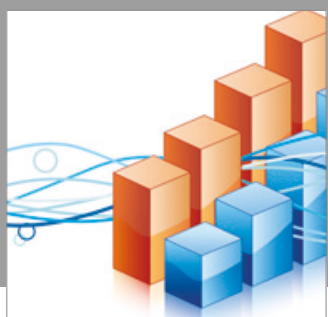

Advances in

Operations Research

vatersals

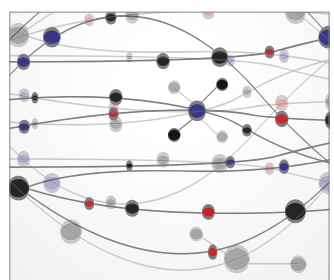

\section{The Scientific} World Journal
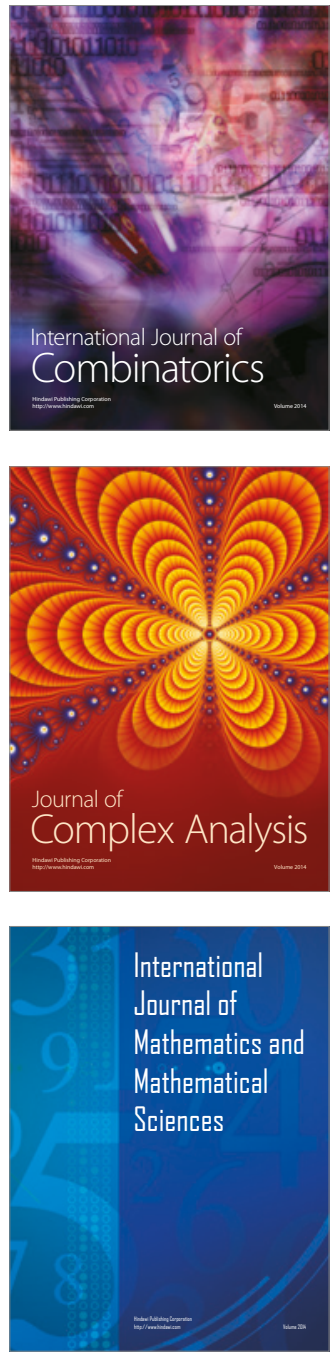
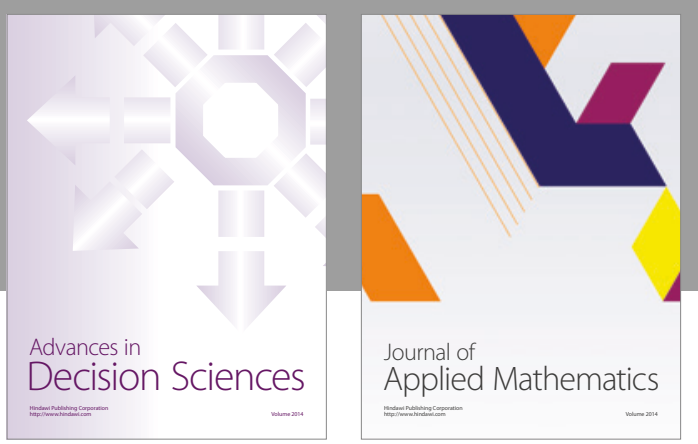

Algebra

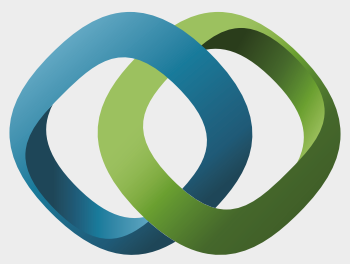

\section{Hindawi}

Submit your manuscripts at

https://www.hindawi.com
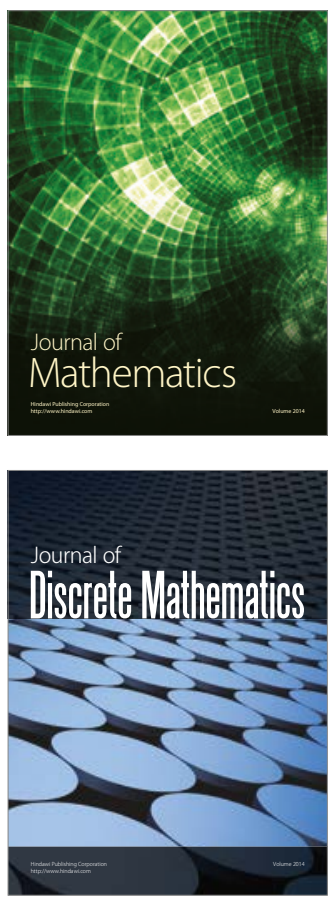

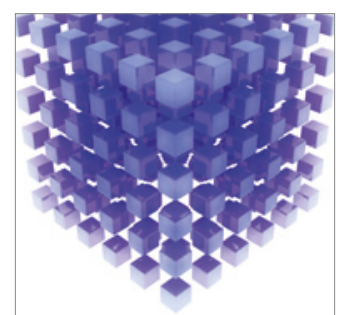

Mathematical Problems in Engineering
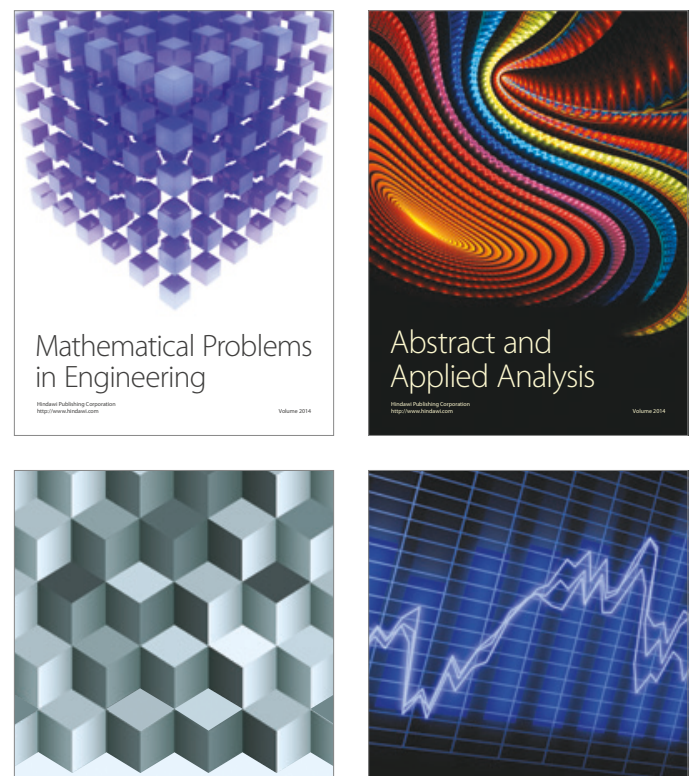

Journal of

Function Spaces

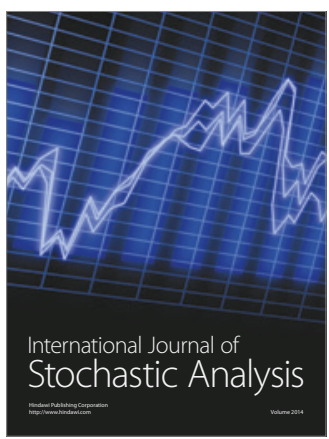

Probability and Statistics
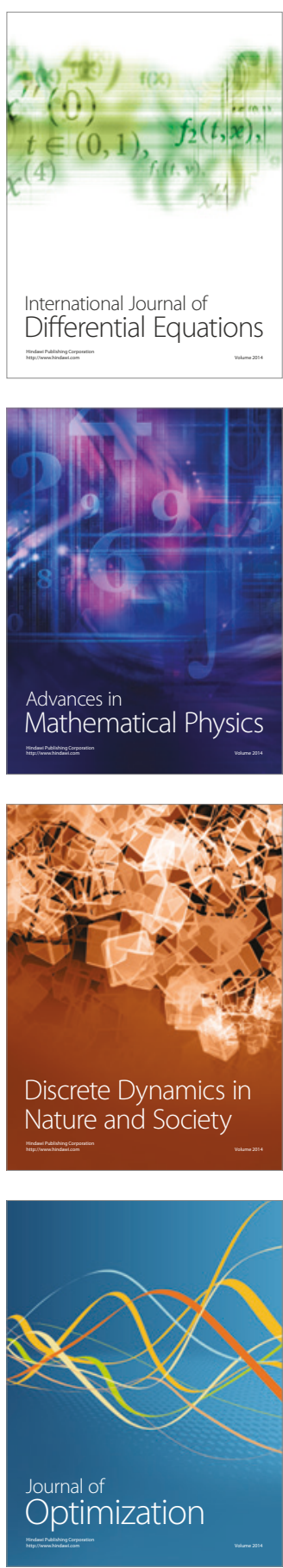